\title{
An assessment of dairy herd bulls in southern Australia: 2. Analysis of bull- and herd-level risk factors and their associations with pre- and postmating breeding soundness results
}

\author{
A. S. Hancock, ${ }^{*}{ }^{1}$ P. J. Younis, $\dagger$ D. S. Beggs, ${ }^{*}$ P. D. Mansell, ${ }^{*}$ M. A. Stevenson, ${ }^{*}$ and M. F. Pyman ${ }^{*}$ \\ *Faculty of Veterinary and Agricultural Sciences, The University of Melbourne, Werribee, Victoria 3030, Australia \\ †The Vet Group, Timboon, Victoria 3268, Australia
}

\begin{abstract}
In pasture-based, seasonally calving dairy herds of southern Australia, the mating period usually consists of an initial artificial insemination period followed by a period of natural service using herd bulls. The primary objective of this study was to identify associations between individual bull- and herd-level management factors and bull fertility as measured by a pre- and postmating bull breeding soundness evaluation (BBSE). Multivariable mixed effects logistic regression models were used to identify factors associated with bulls being classified as high risk of reduced fertility at the premating and postmating BBSE. Bulls older than $4 \mathrm{yr}$ of age at the premating BBSE were more likely to be classified high risk compared with bulls less than $4 \mathrm{yr}$ of age. Bulls that were in herds in which concentrates were fed before mating were more likely to be classified as high risk at the postmating BBSE compared with bulls that were in herds where concentrates were not fed. Univariable analyses also identified areas in need of further research, including breed differences between dairy bulls, leg conformation and joint abnormalities, preventative hoof blocking for bulls, and mating ratios. Key words: dairy herd bull, bull breeding soundness evaluation, lameness, seasonally calving herd
\end{abstract}

\section{INTRODUCTION}

Australian dairy herds have suffered a general decline in overall herd fertility since the early 1990s (Dairy Australia, 2011). Fertility is a key driver of profitability in any dairy herd (De Vries, 2006), and in seasonally calving dairy herds in southern Australia, the fixed duration of the mating period places extra pressure on reproductive performance as compared with herds where calving occurs throughout the year (Roche et al., 2007). Research has been undertaken to identify

Received December 21, 2015.

Accepted August 22, 2016.

${ }^{1}$ Corresponding author: a_s_hancock@hotmail.com risk factors for suboptimal fertility in Australian dairy cows (Dairy Australia, 2011), but with the exception of one unpublished study (Dwyer, 2013a,b), no research investigating the fertility of bulls (that is, bulls used to perform natural service in dairy herds) has been undertaken. To our knowledge, no peer-reviewed studies in any country have investigated factors affecting the fertility of dairy bulls in pasture-based dairy herds. Australian industry recommendations are available for dairy herd bull use and management (InCalf, 2008) but these are largely based on the anecdotal knowledge provided by experienced members of the dairy industry, and although they are still very useful, few empirical data are available on which to develop evidence-based industry recommendations.

Whereas the accuracy of a bull breeding soundness evaluation (BBSE) as a predictor of good fertility has been questioned (Kastelic and Thundathil, 2008), characteristics included in a BBSE have been correlated with bull fertility (Coulter and Kozub, 1989; Bertram et al., 2002; Fitzpatrick et al., 2002; Holroyd et al., 2002; Al-Makhzoomi et al., 2008; Menegassi et al., 2011). Importantly, a BBSE is an excellent tool for identifying bulls that are at high risk of reduced fertility (Kastelic and Thundathil, 2008). Several studies have demonstrated that when multiple sires are run with a herd, a relatively small proportion of bulls sire the majority of calves (Osterhoff, 1966; Lehrer et al., 1977; Holroyd et al., 2002). If a dominant bull is subfertile and prevents fertile, subordinate bulls from mating, then herd fertility may be adversely affected (Petherick, 2005). It is useful therefore to identify characteristics that render bulls more likely to be classified as high risk of reduced fertility at a BBSE because these factors may be able to be mitigated through bull selection and management.

This is the second of 2 papers that present results from a study investigating management practices and pre- and postmating BBSE in southern Australian dairy herds. The first paper describes the management of a cohort of dairy herd bulls and the results of pre- and postmating BBSE, showing that the principal direct cause of bulls being classified as high risk of reduced 
fertility postmating was lameness. This paper identifies associations between individual bull- and herd-level management factors and bull fertility as measured by pre- and postmating BBSE. Our aims were to (1) screen potential risk factors for BBSE abnormalities observed in the study bulls using univariable analyses; (2) identify individual bull-level factors associated with an increased risk of poor fertility as measured by a premating BBSE; and (3) identify herd-level management factors associated with an increased risk of poor fertility as measured by a postmating BBSE. This information should aid in the development of practical recommendations for dairy herd bull selection and management.

\section{MATERIALS AND METHODS}

\section{Animals and Herds}

Bulls from 32 dairy herds were included in the study. Two hundred fifty-six bulls were evaluated premating and 200 bulls were evaluated postmating. The selection and inclusion criteria for animals and herds in the study are described in the companion paper (Hancock et al., 2016).

\section{Bull Breeding Soundness Evaluations and Risk Classifications}

The bulls in the study underwent a premating and postmating BBSE. The procedures used for the premating and postmating BBSE, as well as the allocation of risk categories for "physical," "crush-side semen," "sperm morphology," and "overall" are described in the companion paper (Hancock et al., 2016).

\section{Management Questionnaires}

At each of the BBSE visits, herd managers completed a management questionnaire to describe details of bull management before and during the mating period. The content and delivery of the premating and postmating questionnaires are described in the companion paper (Hancock et al., 2016).

\section{Statistical Analyses}

The variables used in this study were collated from the individual bull information collected at the pre- and postmating BBSE and the herd-level bull management information from the questionnaires (Table 1). For the variables Physical, Sperm_Morphology, and Overall_ BBSE, the result for each bull at the pre- and postmat- ing BBSE was converted into a binary outcome: bulls that were classified as low risk were combined with those in the qualified category and coded 0 , and those in the high-risk category were coded 1 . The rationale for this approach was that any bull classified as low risk or qualified would be recommended as suitable for use, as opposed to high-risk bulls where the recommendation would be not to use that bull. Although the same bulls were evaluated twice, the results of each BBSE were analyzed separately, and not as repeated measures.

Risk Factors Related to Lameness. Analyses were carried out to quantify the unconditional association between the explanatory variables Joints, Leg_Score, and Blocked, with the outcome variable Gait, for both the pre- and postmating BBSE. Separate analyses were carried out for the explanatory variables Leg_Score and Blocked, with the outcome variable Joints (for both pre- and postmating for Leg_Score, only postmating for Blocked). Semen motility and the proportion of sperm classified as normal for lame and sound bulls at the pre- and postmating BBSE were compared (Table 2). Pearson's chi-squared test was used to test the hypothesis that a given (binary) explanatory variable was associated with a given outcome variable. Means were compared using independent $t$-tests. Associations between continuous, ordinal, and dichotomous explanatory variables and the binary outcome variable were quantified using univariable binary logistic regression analyses.

Breed Differences Between Holstein and Jersey Bulls. Analyses were carried out to quantify the unconditional association between the explanatory variable Breed, with the outcome variables Sperm_Morphology and Joints, for both the pre- and postmating BBSE. Separate analyses were carried out to compare semen motility (Motility), the percentage of normal sperm (Normal_Sperm), the percentage of midpiece abnormalities, Leg_Score, BCS, and scrotal circumference for Holstein and Jersey bulls at the preand postmating BBSE, as shown in Table 3. Pearson's chi-square test was used to test the hypothesis that a given (binary) explanatory variable was associated with a given outcome variable. Means were compared using independent $t$-tests.

Mating Ratios. The formulae and rationale used for calculating mating ratios (the ratio of numbers of males to females) are described in the companion paper (Hancock et al., 2016). Herds were grouped into mating ratio categories, and the proportion of high-risk bulls in each category was calculated for the postmating BBSE.

Age. Bulls were grouped into age categories, and the proportion of high-risk bulls (and their binomial confidence limits) for each age category was calculated for the pre- and postmating BBSE. 
Table 1. Definitions of explanatory and outcome variables used in the analyses described in the text

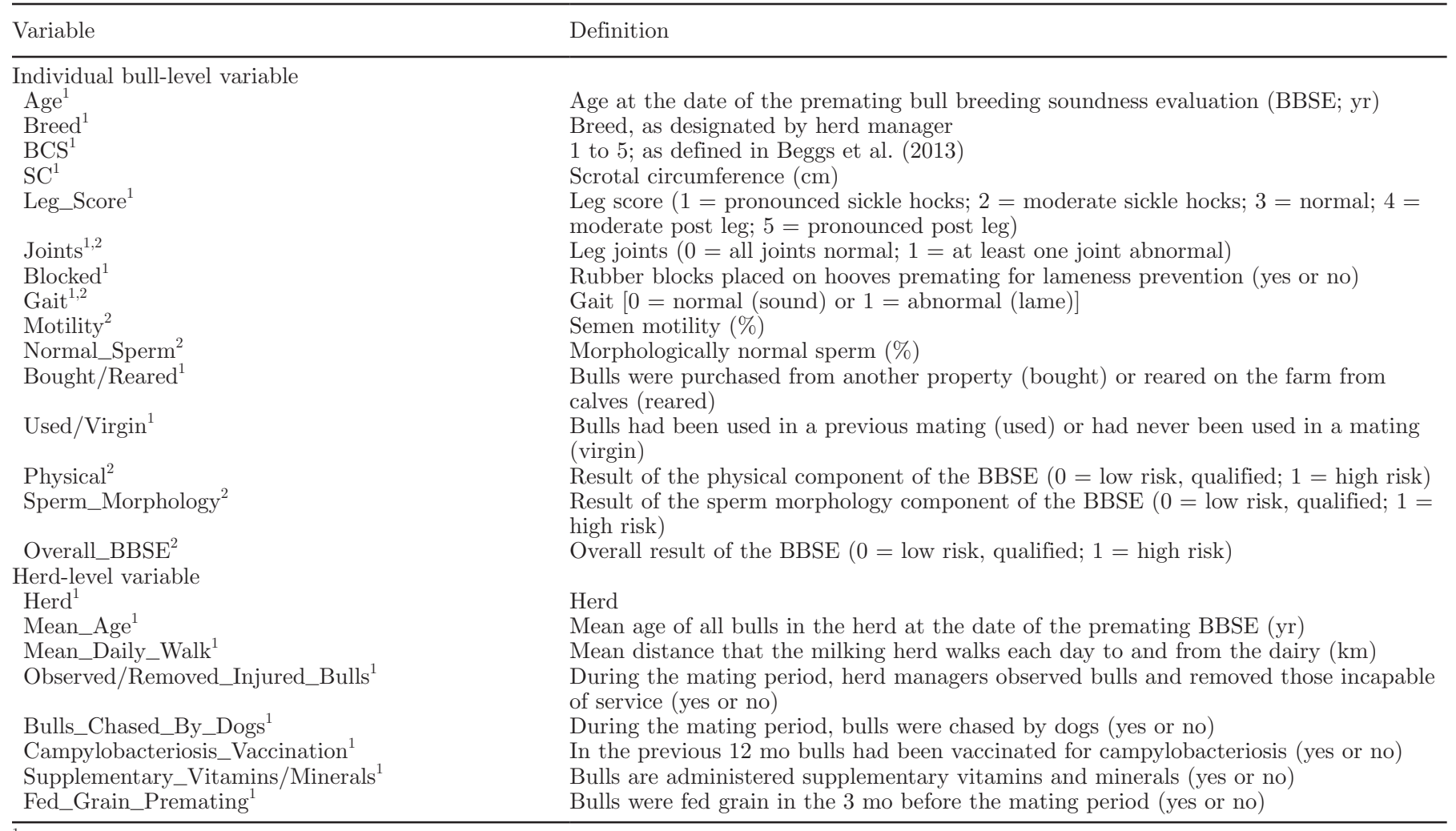

${ }^{1}$ Explanatory variable.

${ }^{2}$ Outcome variable.

\section{Univariable Screening for the Multivariable Analyses}

Univariable analyses were performed to quantify the association between bull-level explanatory variables and the odds of an individual bull being classified as high risk at the premating BBSE. Explanatory variables with unconditional associations with the outcome that were significant at $P<0.25$ level (2-sided) were selected for multivariable modeling. The bull-level variables that remained after screening $(P<0.25)$ were Age, Breed, Leg_Score, Bought/Reared, and Used/Virgin. The continuous/ordinal variables Age and Leg_Score were converted to binary variables (age $<4 \mathrm{yr}, \geq 4 \mathrm{yr}$; leg score $>3, \leq 3)$. The variable Breed was separated into 3 categories: Holstein, Jersey, and other.

Univariable analyses were performed to quantify the association between herd-level explanatory variables and the odds of a bull being classified as high risk at the postmating BBSE. Similar to the approach taken for the premating BBSE, explanatory variables with unconditional associations with the outcome that were significant at $P<0.25$ level (2-sided) were selected for multivariable modeling. The herd-level variables that remained after screening $(P<0.25)$ were Mean_Daily_Walk, Observed/Removed_Injured_Bulls, Bulls_ Chased_By_Dogs, Campylobacteriosis_Vaccination,

Table 2. Pre- and postmating semen assessments for sound and lame bulls ${ }^{1}$

\begin{tabular}{|c|c|c|c|c|c|c|}
\hline BBSE variable & \multicolumn{3}{|c|}{ Premating } & \multicolumn{3}{|c|}{ Postmating } \\
\hline Motility (\%) & 62 & 58 & $3.3(-4.1$ to 11$)$ & 62 & 60 & $1.7(-3.7$ to 7.1$)$ \\
\hline
\end{tabular}

${ }^{1}$ Student's $t$-test to compare means, all $P$-values $>0.05 . \Delta=$ difference between crude means for sound and lame bulls. BBSE $=$ bull breeding soundness evaluation.

${ }^{2}$ Crude means are shown. 
Table 3. Pre- and postmating bull breeding soundness evaluation (BBSE) variables for Holstein and Jersey bulls ${ }^{1}$

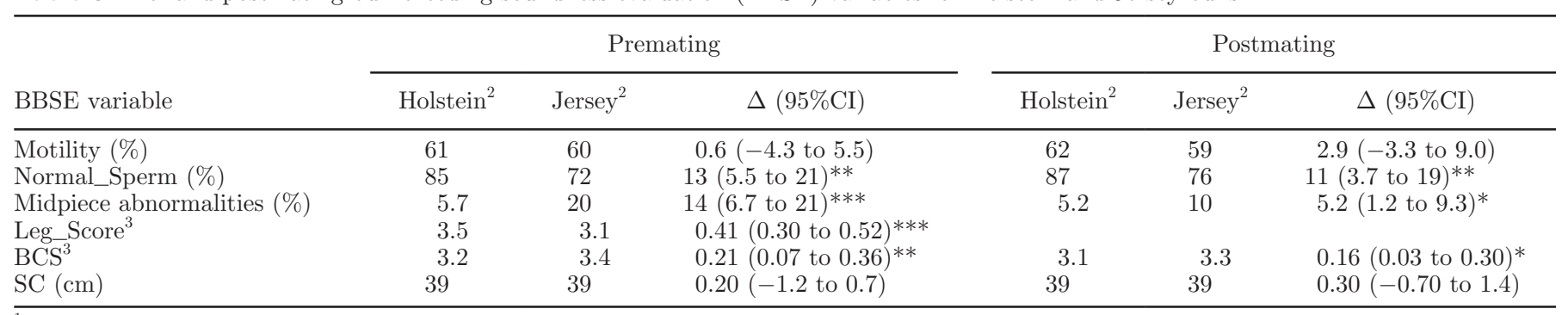

${ }^{1}$ Independent $t$-test to compare means. SC: scrotal circumference. $\Delta=$ difference between crude means for Holstein and Jersey bulls. For comparing means, the ordinal variables Leg_Score and BCS were assumed to be continuous.

${ }^{2}$ Crude means are shown.

${ }^{3}$ Scored on a scale of 1 to 5 .

${ }^{*} P<0.05 ;{ }^{* *} P<0.01 ;{ }^{* * *} P<0.001$.

Supplementary_Vitamins/Minerals, and Fed_Grain_ Premating.

\section{Multivariable Analyses}

A multivariable logistic regression model was developed to quantify the association between each of the hypothesized explanatory variables and the risk of a bull being classified as high risk at the premating BBSE. This was done to quantify the influence of individual bull factors on BBSE result before mating, which may help to develop recommendations for the selection of individual bulls for a given bull team. All of the explanatory variables that had an unconditional association with the outcome at $P<0.25$ were included into a single model. Explanatory variables that were not statistically significant were removed from the model one at a time, beginning with the least significant, until the estimated regression coefficients for all explanatory variables retained were significant at an $\alpha$ level of less than 0.05. A zero mean random effect term for herd was included in the model to account for lack of independence in the data arising from individual bulls clustered within herds.

To identify herd-level variables that were associated with the risk of a bull being classified as high risk in the postmating BBSE, a second multivariable mixed effects logistic regression model was developed using the same approach described for the premating BBSE model. This was done to quantify the association between herd-level management factors and the risk of a bull being classified as high risk at the postmating BBSE, adjusting for the effect of known confounders. Similar to the approach described for the premating BBSE, a zero-mean random effect term for herd was included in the postmating BBSE model to account for lack of independence in the fertility risk classifications arising from clustering of bulls within herds. Bull age was included in the model a priori because it was believed to be a confounder, despite $P \geq 0.05$.

Both of the multivariable logistic regression models were developed using the lme4 package (Bates et al., 2015) implemented in R ( $\mathrm{R}$ Core Team, 2013).

\section{RESULTS AND DISCUSSION}

The animals and herds included in the study, the preand postmating BBSE findings, and the responses to the management questionnaires are discussed in detail in the companion paper (Hancock et al., 2016).

\section{Risk Factors Related to Lameness}

It should be noted that the results of the univariable analyses reported should be interpreted with caution as they have not been adjusted to account for the effect of confounding variables such as bull age and herd. The rationale for presenting these results is that they are biologically plausible and it is our expectation that if this study were to be repeated using a larger number of bulls and herds then the (significant) unconditional associations identified in this study may well be significant after controlling for the effect of known confounders. In this way, the results of this study should prove useful for those designing future observational studies of factors influencing breeding soundness as assessed at pre- and postmating BBSE.

Leg Joints and Leg Score. Compared with bulls with normal leg joints, the odds of lameness at the premating BBSE for bulls with abnormal leg joints was increased by a factor of 8.37 (95\% CI: 3.7 to $18.93 ; P$ $<0.001$ ). Compared with bulls with normal leg joints, the odds of lameness at the postmating BBSE for bulls with abnormal leg joints was increased by a factor of 2.52 (95\% CI: 1.59 to $3.99 ; P<0.001)$. Compared with bulls with normal leg joints at the premating BBSE, 
the odds of lameness at the postmating BBSE for bulls with abnormal leg joints at the premating BBSE was increased by a factor of 1.86 (95\% CI: 1.03 to $3.36 ; P$ $=0.06)$.

For unit increases in leg score (a measure quantifying the straightness of the hind legs), the odds of a bull being lame at the premating BBSE was increased by a factor of 3.20 (95\% CI: 1.30 to $7.88 ; P=0.01$ ). For unit increases in leg score, the odds of a bull having abnormal leg joints at the premating BBSE was increased by a factor of 2.10 (95\% CI: 1.02 to $4.34 ; P=0.045$ ).

Lameness in the bulls studied was most likely to have been caused by a combination of foot-related and joint-related pathology. Because thorough diagnostic examination of lame bulls was not performed, it is not possible to quantify the proportions of bulls that were lame due to each of feet or joint issues. It has been shown in pasture-based dairy systems that over $90 \%$ of lameness in cows is caused by foot lesions (Jubb and Malmo, 1991; Tranter and Morris, 1991; Murray et al., 1996; Chesterton et al., 2008). Because the bulls in our study were exposed to the same risk factors for lameness as the milking cows in our herds, it is likely that a high proportion of lame bulls were lame due to foot-related lesions. It is reasonable to assume that some of the lame bulls with abnormal joints were lame due to a foot-related problem, and vice versa. However, given the association between lameness and joint abnormalities in our study, a proportion of the lameness cases that occurred may be attributable to joint disease.

Lameness at the pre- and postmating BBSE was associated with the presence of swollen leg joints, and increased with the straightness of the hind legs as assessed at the premating BBSE. Hocks made up the majority of swollen joints, probably because they are easiest to visualize and palpate. Definitive diagnoses of the causes of the joint pathology were not obtained, and it is possible that infectious pathogens such as $M y$ coplasma bovis were a cause of some of the swellings. In studies of tarsal swellings in bulls, the most common pathology was degenerative joint disease (Bargai and Cohen, 1992; Dutra et al., 1999; Nichols and Lardé, 2014). Degenerative joint disease and specifically osteochondrosis have been reported in beef and dairy cattle, with and without associated signs of pain or lameness (Bargai and Cohen, 1992; Trostle et al., 1997; Dutra et al., 1999; Persson and Ekman, 2004). The pathophysiological mechanism via which osteochondrosis occurs is complex and not completely understood, although it is an arthropathy involving incomplete endochondral ossification, leading to cartilage necrosis, and can progress to osteochondritis dissecans and osteoarthritis (Nichols and Lardé, 2014). Clinically it manifests as joint effusion and lameness of varying severity (Nichols and Lardé, 2014). The most common osteochondrosis predilection sites in bulls are the stifle and tarsus (Dutra et al., 1999; Nichols and Lardé, 2014). The most commonly implicated predisposing risk factors include rapid growth rates, joint anatomy, trauma, and vitamin and mineral imbalances (Nichols and Lardé, 2014). Osteochondrosis has high heritability, and this may be due to inherited features of joint anatomy, and although trauma is not thought to initiate osteochondrosis, it is reasoned that minor and repetitive trauma increases the severity of the lesions (Nichols and Lardé, 2014).

The relatively high prevalence of joint disease in our study bulls is an important finding. In a study of joint lesions in infertile bulls, Persson et al. (2007) suggests that joint disease (specifically osteoarthritis secondary to osteochondrosis) was a likely contributing factor to the infertility of those bulls. Although unable to verify retrospectively, we hypothesize that the bulls in our study may also have been predisposed to developing osteochondrosis lesions. Increasing the proportion of concentrate in the ration has been shown to increase growth rates in growing dairy-breed bulls (Huuskonen et al., 2007), and given that most bulls in our study were fed energy-dense concentrate between weaning and 12 mo of age (Hancock et al., 2016), their growth rates may have been elevated. We further hypothesize, that if present, these lesions could have been exacerbated by the mating workload, walking on tracks, and standing on concrete yards, ultimately resulting in osteochondrosis, osteoarthritis, and lameness. If present, these effects may be amplified in bulls with straighter legs, where there are changes on the weightbearing angles, and therefore an increase in the concussive forces on the joints. This may also explain the higher prevalence of swollen joints in Holstein bulls, which had significantly straighter legs than Jersey bulls (Table 3). In fact, Holsteins have had selection pressure to increase the straightness of the hock angle, as a lameness prevention measure for cows (van der Waaij et al., 2005). This selection strategy may have inadvertently increased the predisposition to lameness in Holstein herd bulls.

Semen Variables. For assessments of semen motility and percentage of normal spermatozoa, no significant differences were found for sound and lame bulls at either the pre- and postmating BBSE. These results agree with the findings of Persson et al. (2007) who found no increase in morphological sperm defects in bulls with osteoarthritis. An increase in morphological defects has been reported in bulls with injuries (Ellis et al., 2005), and that this may be a result of sperm defects increasing in response to physiological stress (Barth and Bowman, 1994). It is possible that the lameness that occurred in our study bulls was not suf- 
ficiently severe to affect sperm quality, or perhaps the sequential nature of the appearance of sperm defects following the stressor (Barth and Bowman, 1994) meant that observable changes in the spermiogram had not yet occurred at the time of evaluation. It is likely that given the prevalence of lameness seen during and after mating, enough bulls had been lame for long enough for our study to have sufficient statistical power to detect differences in the spermiogram at the postmating BBSE. To confirm this, serial sperm evaluations would be required for several weeks after diagnosing bulls as lame to monitor for the appearance of defects. Further investigation into the effects of lameness on semen variables is warranted.

Preventative Blocking. One lameness prevention measure currently used for bulls in Australia is the use of rubber blocks, which are affixed with adhesive onto all 4 feet before mating. At the postmating BBSE, 55 bulls (from 7 herds) had been preventatively blocked premating, and 145 bulls (from 25 herds) had not been. When comparing groups [no blocks versus blocks (reference group)], we did not observe a significant association with lameness at the postmating BBSE (OR 0.86; 95\% CI: 0.51 to $1.45 ; P=0.57)$. A trend was observed in the association between bulls being blocked and having abnormal leg joints at the postmating BBSE, with the odds increased by a factor of 1.56 (95\% CI: 0.92 to 2.67; $P=0.11)$.

Blocking is a recently introduced practice in our region, and herd managers have claimed that since beginning the practice they have had fewer problems with lameness in their herd bulls. In our study bulls, evidence was insufficient to demonstrate that blocking prevented lameness, and it is possible that blocking was a contributing factor to swollen joints. It might be that the presence of the block alters the normal weight bearing angles of the legs. The blocks had all fallen off by the end of the mating period, and would invariably have fallen off at different times. This may have resulted in a period of imbalance in the foot while there was a block on only one claw, resulting in abnormal stresses on the leg joints. Alternatively, these results may have been influenced by imprecision due to small sample size, and confounding given that the herds that blocked bulls had a historically high prevalence of lameness in their bulls. A randomized clinical trial is required to assess the efficacy of blocks in preventing lameness in herd bulls.

\section{Breed Differences Between Holstein and Jersey Bulls}

A significant difference was found in the proportion of bulls classified as high risk for Sperm_Morphology at both the pre- and postmating BBSE. Premating, the odds were increased in Jersey bulls by a factor of 4.01 (95\% CI: 1.67 to $9.64 ; P<0.001)$. Postmating, the odds were increased in Jersey bulls by a factor of 7.26 (95\% CI: 1.91 to 27.56; $P<0.001$ ). Also, a significant difference occurred in the proportion of bulls in each breed that had abnormal leg joints. Premating a trend was observed in the association between breed and abnormal leg joints, with the odds increased by 2.84 in Holstein bulls (95\% CI: 0.9 to $9.0 ; P=0.054$ ). Postmating, Holstein bulls had an 11.42 times greater odds of having abnormal joints (95\% CI: 1.62 to 80.42; $P<0.001)$. Breed differences for ordinal and continuous variables at the pre- and postmating BBSE are shown in Table 3.

Apart from the previously discussed differences between Holstein and Jersey bulls with respect to hind leg straightness, the 2 breeds differed significantly in sperm quality. Jersey bulls had significantly lower percentages of morphologically normal sperm compared with Holstein bulls, and this difference was due to the effect of the significantly increased numbers of midpiece defects in Jersey bulls. Some studies have found differences in semen quality between Holsteins and Jerseys (Kasimanickam et al., 2006), and differences between Holsteins and other breeds (Hoflack et al., 2006). It is possible that the $P$-value we calculated is artificially low due to the failure of a univariable analysis to account for the clustering effect of herd. Alternatively, a genetic component may be contributing to the propagation of Jersey bulls with high numbers of midpiece defects in their ejaculate. Therefore, it might be a sound strategy to cull any Jersey bulls that repeatedly demonstrate this abnormality. Further research is warranted to investigate the prevalence of morphological defects in Australian Jersey sires.

\section{Mating Ratios}

The traditional meaning of a bull mating ratio (the ratio of bulls to nonpregnant cows) is problematic in Australian seasonally calving, pasture-based dairy herds. Bulls are generally used for a period of a few weeks or months following an AI mating period. It is common practice to use bull teams of varying sizes from which bulls are regularly rotated in and out of the herd. For these reasons, a meaningful mating ratio is difficult to calculate. Thus, the Australian industry recommendation is to use the ratio of the total number of bulls in the bull team as a proportion of herd size at the beginning of the AI mating period, rather than the number of bulls actually in with the herd as a proportion of nonpregnant cows during the natural mating period. 
The mean prevalence of high-risk bulls per herd (as assessed at the postmating BBSE) for mating ratios of 1 to $2 \%, 2$ to $3 \%$, and $\geq 3 \%$ is shown in Figure 1 . Current Australian industry recommendations for the mating ratio for dairy herd bulls are 3 to $4 \%$ (InCalf, 2008). That is, 3 bulls in the entire bull team per 100 cows present at the mating start date (start of the AI period), or $4 \%$ (4 bulls per 100 cows) if whole herd synchrony programs are used. These recommendations were determined by representatives of the local industry with extensive experience, and they are similar to ratios described in conference proceedings that discuss the management of dairy herd bulls (Risco et al., 1998, 2011; Champagne et al., 2002; Chenoweth et al., 2003; Dwyer, 2013b). Using this approach for determining mating ratio, a numerically reduced proportion of bulls were classified as high risk postmating in herds with a mating ratio of at least $3 \%$ (Figure 1). The herds in our study tended to have lower ratios than the industry recommendation, although if mating ratio was retrospectively calculated accounting for the number of cows that were pregnant at the end of the AI period (that is, the number of bulls in the entire bull team divided by the number of nonpregnant cows at the end of the AI period), then the mean mating ratio for the study herds was approximately $6.4 \%$. The latter ratio, however, is difficult to apply practically, as the number of bulls required for the natural mating period needs to be determined before it is possible to estimate the number of cows that are nonpregnant following the AI period.

A caveat to any mating ratio recommendation should be that increasing the mating ratio will not necessarily compensate for a high prevalence of high risk and qualified bulls in the bull team. For example, it has been shown that socially dominant bulls are able to sire more calves than less dominant bulls (Fordyce et al., 2002). If there are dominant bulls with risk factors for infertility such as lameness, penile injuries, or a high prevalence of uncompensable sperm defects, having a larger number of sound bulls in the bull team may not necessarily compensate for the inadequacies of the dominant bulls. Even if the same numbers of conceptions are achieved, they may occur later in the mating period, resulting in late calving cows which are less likely to conceive in the subsequent mating period (Morton, 2010). It is apparent from our data that the current industry recommendations may result in high mating ratios of bulls to nonpregnant cows after the AI period, and may also result in changes in social hierarchy due to the recommendation to rotate bulls weekly (InCalf, 2008). Both of these are risk factors for inter-bull aggression and resultant injuries (Fordyce et al., 2002; Petherick, 2005). The current recommendations on mating ratios may need to be revised to account for these factors.

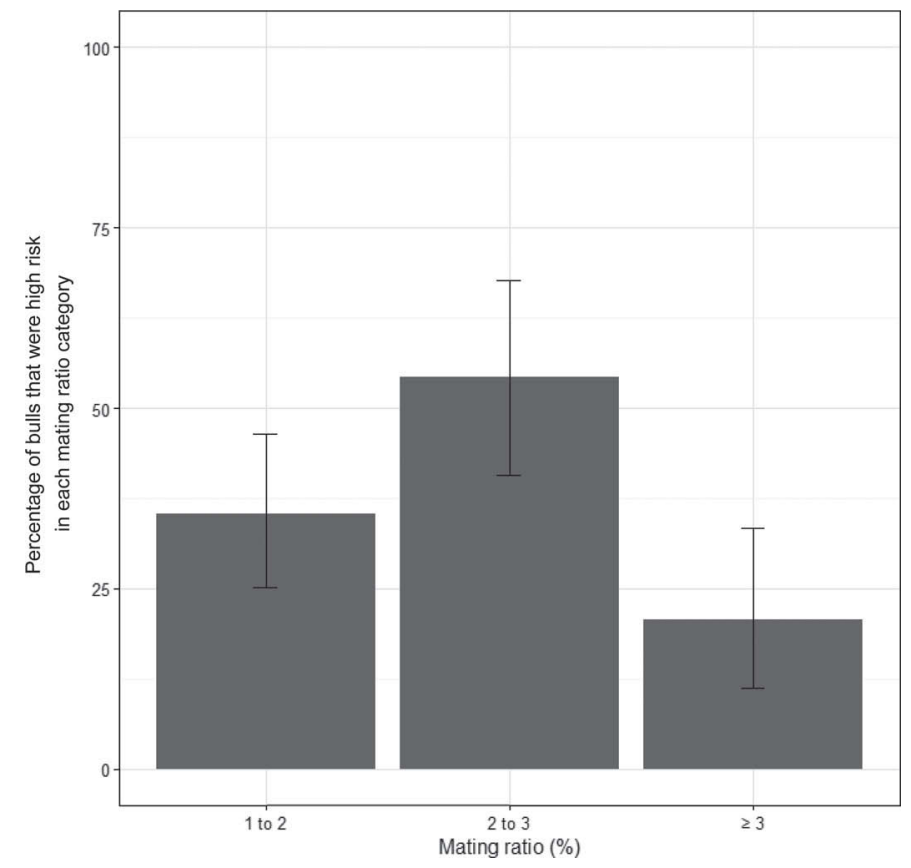

Figure 1. Percentage of bulls that were high risk (and 95\% CI) as assessed at the postmating bull breeding soundness evaluation for mating ratios of 1 to $2 \%, 2$ to $3 \%$, and $\geq 3 \%$.

\section{Age}

The percentage of high-risk bulls by age category at the pre- and postmating BBSE is presented in Figure 2. As age increased the prevalence of bulls classified as high risk at both the pre- and postmating BBSE increased. These results are discussed further in the following section.

\section{Bull-Level Multivariable Model for the Premating BBSE}

The final premating multivariable model is shown in Table 4. After adjusting for the effect of herd, bulls $4 \mathrm{yr}$ of age and older had 2.16 (95\% CI: 1.06 to 4.43 ) times the odds of being classified high risk at the premating BBSE compared with bulls that were under $4 \mathrm{yr}$ of age. These results, along with those displayed in Figure 2, indicate that $4 \mathrm{yr}$ of age is a reasonable threshold for maximum age when selecting bulls in southern Australian dairy herds.

The effect of age on the potential fertility of a bull has been extensively researched, although the results of this research vary. Several authors report that semen traits improve or remain constant with age (Chenoweth et al., 1984; Menon et al., 2011; Söderquist et al., 1996), but postmortem studies of genital abnormalities in Australian beef bulls demonstrate that as age increases so does the prevalence of abnormalities and infections of the penis, testicles, and accessory sex glands (Ladds 


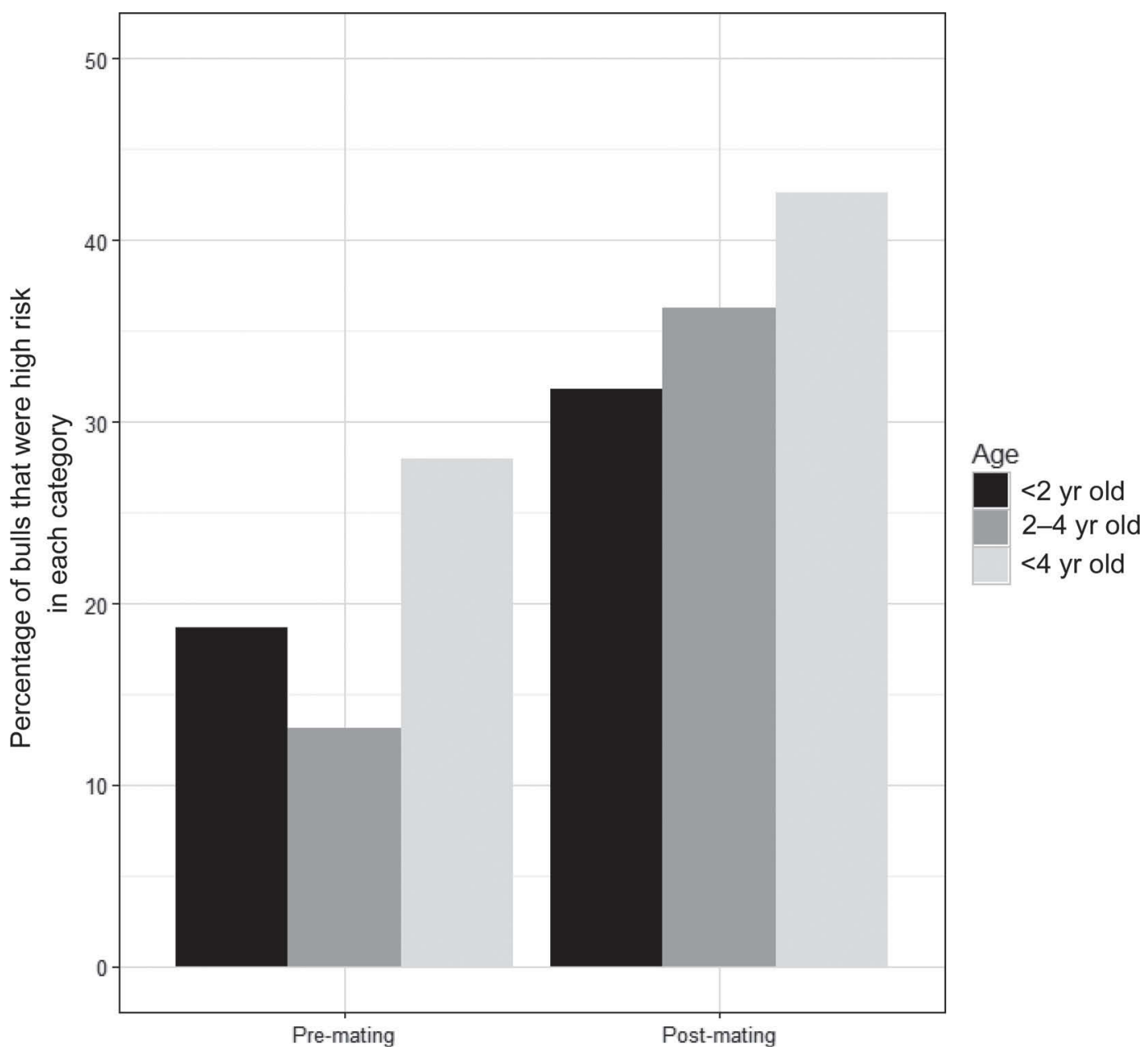

Figure 2. Percentage of bulls that were high risk by age category at the pre- and postmating bull soundness examination.

et al., 1973; Bagshaw and Ladds, 1974), as well as the prevalence of histological degenerative changes in the testes (Humphrey and Ladds, 1975). The effect of age on BBSE results also varies, with studies reporting increasing numbers of rejections with age (McCosker et al., 1989; Menegassi et al., 2012), and no change in
BBSE result with age (Chacón et al., 1999; Waldner et al., 2010).

Reasons for the increase in the proportion of bulls classified as high risk associated with age may include the increased chance of acquiring pathologies of the reproductive tract, as previously discussed, an increased

Table 4. Estimated regression coefficients and their SE from the final mixed effects logistic regression model of factors associated with the risk of a bull being classified as high risk at the premating bull breeding soundness evaluation (BBSE)

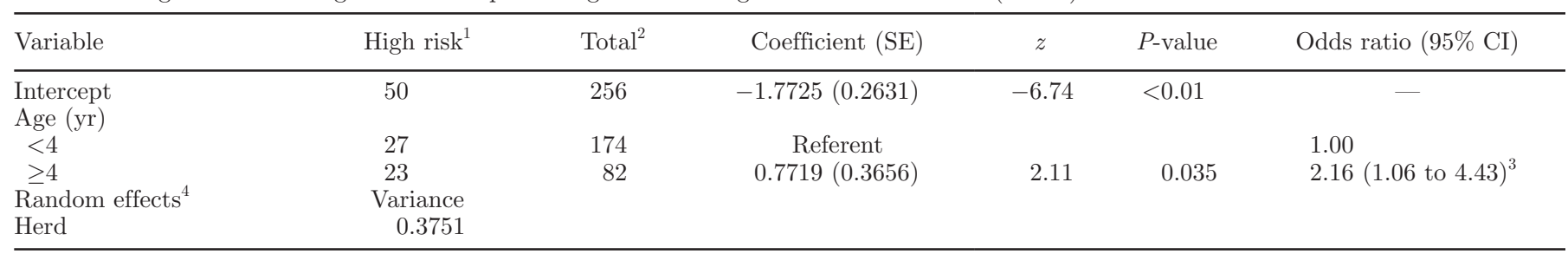

${ }^{1}$ Number of bulls classified as high risk at the premating BBSE.

${ }^{2}$ Total number of bulls.

${ }^{3}$ Interpretation: After adjusting for the effect of herd, the odds of being classified as high risk for bulls that were 4 yr of age or greater was 2.16 (95\% CI: 1.06 to 4.43$)$ times that of bulls that were less than 4 yr of age.

${ }^{4}$ Variance of the herd-level random effect term. 
risk of foot-related lameness with increasing age (Jubb and Malmo, 1991; Tranter and Morris, 1991), and an increased likelihood that bulls are carrying chronic injuries such as osteochondritis dissecans and osteoarthritis lesions in leg joints, and vertebral osteophytosis (Weisbrode et al., 1982). There may also be other benefits of using younger bulls including that they are smaller and therefore safer to handle, and that they are less likely to exert social dominance in multi-sire groups (Petherick, 2005). These results support the current industry recommendations (InCalf, 2008) to use bulls between the ages of $15 \mathrm{mo}$ and $4 \mathrm{yr}$ of age.

\section{Herd-Level Multivariable Model for the Postmating BBSE}

The final postmating multivariable model is shown in Table 5. After adjusting for the effect of bull age and herd, bulls that were in herds where grain was fed in the 3 mo before mating had 3.81 (95\% CI: 1.02 to 14.6) times the odds of being classified as high risk compared with bulls in herds where no grain was fed.

A herd bull does not have the same nutritional requirements as that of a lactating cow, and the NRC states that the requirements of a mature bull are comparable to the ration of a dry dairy cow (NRC, 2001). Feeding lactating cow concentrate formulations (which are high in energy, protein, calcium, and phosphorus) to herd bulls can have potential repercussions including excessive condition, acidosis (and its sequelae), and bony changes resulting from the excessive energy and altered calcium to phosphorus ratios in the diet. Overconditioned bulls may have reduced libido (Petherick, 2005) and have more scrotal fat, which can hinder testicular thermoregulation and result in reduced semen quality (Kastelic et al., 1996). There is also evidence that overfeeding young bulls can impair their semen quality (Coulter et al., 1997). Concentrate feeding can lead to ruminal acidosis, a sequel of which is laminitis (Plaizier et al., 2008), which is a risk factor for many of the common foot lesions causing lameness in dairy cows (Nocek, 1997). Results of a recent study even indicated that a single ruminal acidosis event can cause a prolonged decrease in semen quality (Callaghan et al., 2014). Grain can be high in phosphorus, and diets with low calcium to phosphorus ratios have been shown to predispose to osteoarthritis and lameness (Heinola et al., 2006). Other vitamin and mineral imbalances have also been associated with osteochondritis dissecans (Davies and Munro, 1999). It is important to note that because we did not quantify the actual amount of grain fed daily to the study bulls, we were unable to assess whether there was a dose-response association between the amount of grain offered and the risk of a bull being high risk. Given the wide variety of possible effects of grain-feeding herd bulls, this practice and its association with bull fertility should be investigated further.

Although the other screening variables did not remain in the final model, they still warrant further comment as to their possible effect on the postmating BBSE result. Given that the major cause of postmating failure was lameness, the variables Mean_Daily_Walk and Bulls_Chased_By_Dogs, which were significant in the univariable analyses, are of particular interest. For each increase of $1 \mathrm{~km}$ in the average distance the herd walked each day, the odds of a bull being classified as high risk postmating increased by a factor of 1.26 (95\% CI: $1.03-1.54 ; P=0.028)$. It is reasonable to expect that if a bull is walking long distances each day on gravel tracks, in addition to his mating duties, he will be at a higher risk of becoming lame during the mating period. One of the biggest risk factors for dairy cows becoming lame in pasture-based systems is related to walking on tracks (Harris et al., 1988), and

Table 5. Estimated regression coefficients and their SE from the final mixed effects logistic regression model of factors associated with the risk of a bull being classified as high risk at the postmating bull breeding soundness evaluation (BBSE)

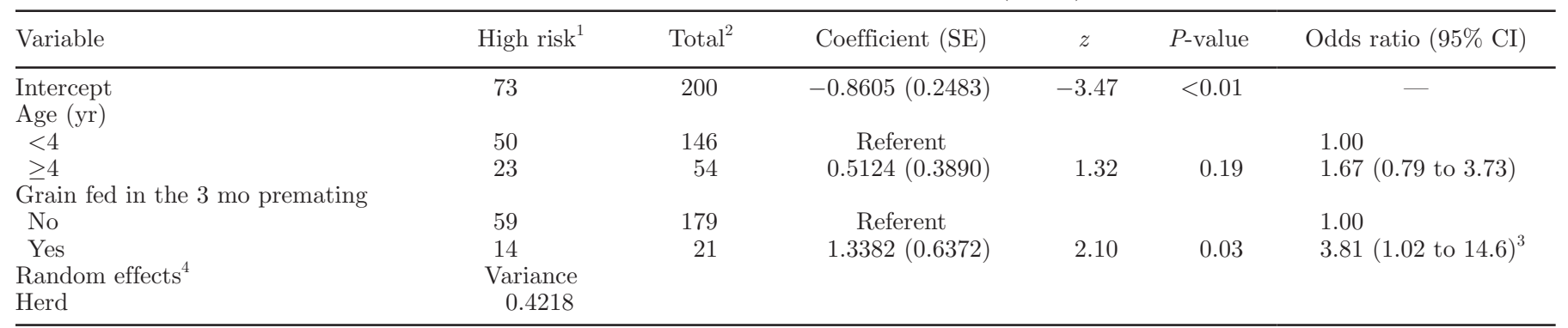

${ }^{1}$ Number of bulls classified as high risk at the postmating BBSE.

${ }^{2}$ Total number of bulls.

${ }^{3}$ Interpretation: After adjusting for the age of the bull and the effect of herd, the odds of a bull being classified as high risk at the postmating BBSE where grain was fed in the 3 mo premating was 3.81 (95\% CI: 1.02 to 14.6) times that of bulls where grain was not fed premating.

${ }^{4}$ Variance of the herd-level random effect term. 
with increasing track length exposure to this risk factor is increased. In herds where bulls were chased by dogs, the odds of a bull being classified high risk postmating was increased by a factor of 2.27 (95\% CI: 1.08-4.79; $P=0.031)$, compared with herds where bulls were not chased by dogs. This has been identified as a risk factor for lameness in dairy cows in pasture-based herds (Chesterton et al., 1989) and logically should also apply to herd bulls.

We have not made strong conclusions for some key management areas, and these need further investigation, including mating ratios, rotation policies, and preventative blocking. Further quantification of the ideal mating ratio of bulls to nonpregnant females at the start of the bull mating period, as well as the ideal mating ratio of bulls actually in with the herd at any one time, would be of benefit to the Australian dairy industry. Herd managers often ask what the appropriate use and rest periods are for herd bulls, and whether or not to rotate them at all. The rotation policies used in this study were not strongly associated with better or worse performance in a BBSE, possibly because not enough herds did not rotate bulls. Although some information on the use of preventative blocks has been presented in this study, we propose that as the uptake of this practice continues to increase, a randomized clinical trial is required to quantify their effect on the risk of lameness. The paucity of scientific literature on the use of natural service dairy bulls definitely justifies further investment in research.

\section{CONCLUSIONS}

We conclude that bulls to be run with pasture-based, seasonally calving dairy herds at the end of the artificial mating period should be less than $4 \mathrm{yr}$ of age. Bulls that were in herds in which concentrates were fed before mating were more likely to be classified as high risk at the postmating BBSE. Interestingly, no association was observed between lameness and semen variables. Univariable analyses identified areas in need of further research, including breed differences between dairy bulls, leg conformation and joint abnormalities, preventative hoof blocking for bulls, and mating ratios. The health and reproductive performance of dairy herd bulls is an important, yet neglected, area of dairy science, and to develop reliable, evidence-based industry recommendations, this topic requires further investigation.

\section{ACKNOWLEDGMENTS}

The authors acknowledge the support of the participating herds, The Vet Group (Timboon, Australia), Dairy Australia (Melbourne, Australia), Gardiner Foundation (Melbourne, Australia), the University of Melbourne (Melbourne, Australia), and Chenovet (Wagga Wagga, Australia).

\section{REFERENCES}

Al-Makhzoomi, A., N. Lundeheim, M. Håård, and H. Rodríguez-Martínez. 2008. Sperm morphology and fertility of progeny-tested AI dairy bulls in Sweden. Theriogenology 70:682-691.

Bagshaw, P., and P. Ladds. 1974. A study of the accessory sex glands of bulls in abattoirs in northern Australia. Aust. Vet. J. 50:489-495.

Bargai, U., and R. Cohen. 1992. Tarsal lameness of dairy bulls housed at two artificial insemination centers: 24 cases (1975-1987). J. Am. Vet. Med. Assoc. 201:1068-1069.

Barth, A. D., and P. A. Bowman. 1994. The sequential appearance of sperm abnormalities after scrotal insulation or dexamethasone treatment in bulls. Can. Vet. J. 35:93-102.

Bates, D., M. Maechler, B. Bolker, and S. Walker. 2015. lme4: Linear mixed-effects models using Eigen and S4. R package version 1.1-9 ed.

Beggs, D. S., J. D. Bertram, P. J. Chenoweth, K. W. Entwistle, G. Fordyce, H. Johnston, P. Johnston, M. R. McGowan, G. Niethe, S. Norman, and V. E. A. Perry. 2013. Veterinary bull breeding soundness evaluation. Eight Mile Plains, Queensland Australian Cattle Veterinarians, 2013.

Bertram, J., G. Fordyce, M. McGowan, G. Jayawardhana, L. Fitzpatrick, V. Doogan, J. De Faveri, and R. Holroyd. 2002. Bull selection and use in northern Australia: 3. Serving capacity tests. Anim. Reprod. Sci. 71:51-66.

Callaghan, M., P. McAuliffe, and V. E. A. Perry. 2014. Sperm morphology: A pain in the gut? Australian Cattle Vets Journal 72:16.

Chacón, J., E. Perez, E. Müller, L. Söderquist, and H. Rodriguez-Martinez. 1999. Breeding soundness evaluation of extensively managed bulls in Costa Rica. Theriogenology 52:221-231.

Champagne, J. D., J. H. Kirk, and J. P. Reynolds. 2002. Bull management practices on California dairies: Implications for education and veterinary services. Pages 15-21 in Proc. 15th Annual Fall Symposium, Univ. California, Davis.

Chenoweth, P. J., J. D. Champagne, and J. F. Smith. 2003. Managing Herd Bulls In Large Dairies. in Proc. 6th Western Dairy Management Conference, Reno, NV.

Chenoweth, P. J., P. Farin, E. Mateos, G. Rupp, and J. Pexton. 1984. Breeding soundness and sex drive by breed and age in beef bulls used for natural mating. Theriogenology 22:341-349.

Chesterton, R. N., K. Lawrence, and R. Laven. 2008. A descriptive analysis of the foot lesions identified during veterinary treatment for lameness on dairy farms in north Taranaki. N. Z. Vet. J. $56: 130-138$.

Chesterton, R. N., D. Pfeiffer, R. Morris, and C. Tanner. 1989. Environmental and behavioural factors affecting the prevalence of foot lameness in New Zealand dairy herds-A case-control study. N. Z. Vet. J. 37:135-142.

Coulter, G. H., R. Cook, and J. Kastelic. 1997. Effects of dietary energy on scrotal surface temperature, seminal quality, and sperm production in young beef bulls. J. Anim. Sci. 75:1048-1052.

Coulter, G. H., and G. Kozub. 1989. Efficacy of methods used to test fertility of beef bulls used for multiple-sire breeding under range conditions. J. Anim. Sci. 67:1757-1766.

Dairy Australia. 2011. InCalf Fertility Data Project 2011. Dairy Australia, Melbourne, Australia.

Davies, I., and R. Munro. 1999. Osteochondrosis in bull beef cattle following lack of dietary mineral and vitamin supplementation. Vet. Rec. 145:232-233.

De Vries, A. 2006. Economic value of pregnancy in dairy cattle. J. Dairy Sci. 89:3876-3885.

Dutra, F., J. Carlsten, and S. Ekman. 1999. Hind limb skeletal lesions in 12-month-old bulls of beef breeds. J. Vet. Med. Ser. A $46: 489-508$.

Dwyer, C. 2013a. Dairy bulls - Why and how we should be testing them. Pages 163-167 in Proc. Australian Cattle Veterinarians Conference, Darwin, NT. 
Dwyer, C. 2013b. Results of an investigation into dairy herd bull breeding soundness and management in Tasmania. Pages 123-126 in Proc. Australian Cattle Veterinarians Conference, Darwin, NT.

Ellis, R., G. P. Rupp, P. Chenoweth, L. Cundiff, and D. Lunstra. 2005. Fertility of yearling beef bulls during mating. Theriogenology 64:657-678.

Fitzpatrick, L., G. Fordyce, M. McGowan, J. Bertram, V. Doogan, J. De Faveri, R. Miller, and R. Holroyd. 2002. Bull selection and use in northern Australia: Part 2. Semen traits. Anim. Reprod. Sci. 71:39-49.

Fordyce, G., L. Fitzpatrick, N. Cooper, V. Doogan, J. De Faveri, and R. Holroyd. 2002. Bull selection and use in northern Australia: 5. Social behaviour and management. Anim. Reprod. Sci. 71:81-99.

Hancock, A., P. Younis, D. Beggs, P. Mansell, and M. Pyman. 2016. An assessment of dairy herd bulls in southern Australia: 1. Management practices and bull breeding soundness evaluations. J. Dairy Sci. 99:9983-9997. http://dx.doi.org/10.3168/jds.2015-10493.

Harris, D., C. Hibburt, G. Anderson, P. Younis, D. Fitspatrick, A Dunn, I. Parsons, and N. McBeath. 1988. The incidence, cost and factors associated with foot lameness in dairy cattle in south-western Victoria. Aust. Vet. J. 65:171-176.

Heinola, T., E. Jukola, P. Näkki, and A. Sukura. 2006. Consequences of hazardous dietary calcium deficiency for fattening bulls. Acta Vet. Scand. 48:25.

Hoflack, G., A. Van Soom, D. Maes, A. De Kruif, G. Opsomer, and L. Duchateau. 2006. Breeding soundness and libido examination of Belgian Blue and Holstein Friesian artificial insemination bulls in Belgium and The Netherlands. Theriogenology 66:207-216.

Holroyd, R., V. Doogan, J. De Faveri, G. Fordyce, M. McGowan, J. Bertram, D. Vankan, L. Fitzpatrick, G. Jayawardhana, and R. Miller. 2002. Bull selection and use in northern Australia: 4. Calf output and predictors of fertility of bulls in multiple-sire herds. Anim. Reprod. Sci. 71:67-79.

Humphrey, J., and P. Ladds. 1975. A quantitative histological study of changes in the bovine testis and epididymis associated with age. Res. Vet. Sci. 19:135-141.

Huuskonen, A., H. Khalili, and E. Joki-Tokola. 2007. Effects of three different concentrate proportions and rapeseed meal supplement to grass silage on animal performance of dairy-breed bulls with TMR feeding. Livest. Sci. 110:154-165.

InCalf. 2008. Bulls power up!: Adviser Handbook. Dairy Australia, Melbourne, Australia.

Jubb, T., and J. Malmo. 1991. Lesions causing lameness requiring veterinary treatment in pasture-fed dairy cows in East Gippsland. Aust. Vet. J. 68:21-24.

Kasimanickam, R., R. Nebel, I. Peeler, W. Silvia, K. Wolf, A. McAllister, and B. Cassell. 2006. Breed differences in competitive indices of Holstein and Jersey bulls and their association with sperm DNA fragmentation index and plasma membrane integrity. Theriogenology 66:1307-1315.

Kastelic, J., R. Cook, G. Coulter, and R. Saacke. 1996. Insulating the scrotal neck affects semen quality and scrotal/testicular temperatures in the bull. Theriogenology 45:935-942.

Kastelic, J., and J. Thundathil. 2008. Breeding soundness evaluation and semen analysis for predicting bull fertility. Reprod. Domest. Anim. 43:368-373.

Ladds, P., D. Dennett, and J. Glazebrook. 1973. A survey of the genitalia of bulls in northern Australia. Aust. Vet. J. 49:335-340.

Lehrer, A. R., M. B. Brown, H. Schindler, Z. Holzer, and B. Larsen. 1977. Paternity tests in multisired beef herds by blood grouping. Acta Vet. Scand. 18:433-441.

McCosker, T., A. Turner, C. McCool, T. Post, and K. Bell. 1989. Brahman bull fertility in a north Australian rangeland herd. Theriogenology 32:285-300.

Menegassi, S. R. O., J. O. J. Barcellos, V. N. Lampert, J. B. S. Borges, and V. Peripolli. 2011. Bioeconomic impact of bull breeding soundness examination in cow-calf systems. Rev. Bras. Zootec. 40:441-447.

Menegassi, S. R. O., J. O. J. Barcellos, V. Peripolli, J. B. S. Borges, and M. L. Bernardi. 2012. Causes of rejection of beef bulls in breeding soundness evaluation. Rev. Bras. Zootec. 41:1648-1653.
Menon, A. G., H. W. Barkema, R. Wilde, J. P. Kastelic, and J. C. Thundathil. 2011. Associations between sperm abnormalities, breed, age, and scrotal circumference in beef bulls. Can. J. Vet. Res. 75:241-247.

Morton, J. 2010. Interrelationships between herd-level reproductive performance measures based on intervals from initiation of the breeding program in year-round and seasonal calving dairy herds. J. Dairy Sci. 93:901-910.

Murray, R., D. Downham, M. Clarkson, W. Faull, J. Hughes, F. Manson, J. Merritt, W. Russell, J. Sutherst, and W. Ward. 1996. Epidemiology of lameness in dairy cattle: Description and analysis of foot lesions. Vet. Rec. 138:586-591.

Nichols, S., and H. Lardé. 2014. Noninfectious joint disease in cattle. Vet. Clin. North Am. Food Anim. Pract. 30:205-223.

Nocek, J. E. 1997. Bovine acidosis: Implications on laminitis. J. Dairy Sci. 80:1005-1028.

NRC. 2001. Nutrient Requirements of Dairy Cattle. 7th ed. National Academy Press, Washington, DC.

Osterhoff, D. R. 1966. Recent developments in blood-group studies in domestic animals. Proc. S. Afr. Soc. Anim. Prod. 5:174-185.

Persson, Y., and S. Ekman. 2004. Osteochondrosis in beef sires in Sweden. Abstract 438 in Proc. World Buiatric Congress. World Association for Buiatrics, Quebec, Canada. Accessed Dec. 15, 2013. http://www.ivis.org/proceedings/wbc/wbc2004/abstr_401_500. htm.

Persson, Y., L. Söderquist, and S. Ekman. 2007. Joint disorder; a contributory cause to reproductive failure in beef bulls? Acta Vet. Scand. 49:31.

Petherick, J. 2005. A review of some factors affecting the expression of libido in beef cattle, and individual bull and herd fertility. Appl. Anim. Behav. Sci. 90:185-205.

Plaizier, J., D. Krause, G. Gozho, and B. McBride. 2008. Subacute ruminal acidosis in dairy cows: The physiological causes, incidence and consequences. Vet. J. 176:21-31.

R Core Team. 2013. R: A language and environment for statistical computing. R Foundation for Statistical Computing, Vienna, Austria. http://www.R-project.org/.

Risco, C., F. Lima, and J. E. Santos. 2011. Management Considerations of Natural Service Breeding Programs in Dairy Herds. Vol. 2015. Accessed Oct. 10, 2013. http://extension.vetmed.ufl.edu/ files /2012/04/Management-Considerations-of-Natural-ServiceBreeding-Programs-in-Dairy-Herds_Risco.pdf.

Risco, C. A., P. J. Chenoweth, B. I. Smith, J. S. Velez, and R. Barker. 1998. Management and economics of natural service bulls in dairy herds. In Compendium on Continuing Education for the Practising Veterinarian-North American Edition. 20:385-390.

Roche, J., K. Macdonald, C. Burke, J. Lee, and D. Berry. 2007. Associations among body condition score, body weight, and reproductive performance in seasonal-calving dairy cattle. J. Dairy Sci. 90:376-391.

Söderquist, L., L. Janson, M. Håård, and S. Einarsson. 1996. Influence of season, age, breed and some other factors on the variation in sperm morphological abnormalities in Swedish dairy AI bulls. Anim. Reprod. Sci. 44:91-98.

Tranter, W., and R. Morris. 1991. A case study of lameness in three dairy herds. N. Z. Vet. J. 39:88-96.

Trostle, S. S., R. Nicoll, L. Forrest, and M. Markel. 1997. Clinical and radiographic findings, treatment, and outcome in cattle with osteochondrosis: 29 cases (1986-1996). J. Am. Vet. Med. Assoc. 211:1566-1570.

van der Waaij, E., M. Holzhauer, E. Ellen, C. Kamphuis, and G. De Jong. 2005. Genetic parameters for claw disorders in Dutch dairy cattle and correlations with conformation traits. J. Dairy Sci. 88:3672-3678.

Waldner, C. L., R. I. Kennedy, and C. W. Palmer. 2010. A description of the findings from bull breeding soundness evaluations and their association with pregnancy outcomes in a study of western Canadian beef herds. Theriogenology 74:871-883.

Weisbrode, S., D. Monke, S. Dodaro, and B. Hull. 1982. Osteochondrosis, degenerative joint disease, and vertebral osteophytosis in middle-aged bulls. J. Am. Vet. Med. Assoc. 181:700. 